\title{
On the Illustration Design of Children's Books
}

\author{
Zhiwen Tian \\ Department of Design, Hubei Institute of Fine Arts, China
}

Keywords: children, books, illustration.

\begin{abstract}
Childhood is the most important shaping phase in a person's life. Reading is an important way for children to know and understand the world. People of different ages also need different books. For children, they need children's books and engaging children's books. In childhood, the most important feature of reading is reading pictures. The importance of children's book illustrations has long gone far beyond those illuminated texts. Illustrations can not only clearly express the content, but also have certain artistry to improve the overall style of the book. The development of book illustrations is constantly updated and progressed. Either using traditional brush tools or emerging computers, the truly outstanding children's illustrations are not only used to convey information, but also to enable children to be influenced by art, as well as to contribute to the development of children's thinking ability, imagination and aesthetic ability.
\end{abstract}

\section{The Features of Children's Reading}

The design of children's book needs to meet the children's psychological development features and their reading habits. However, the features of children's psychological development change with their age. Children have childlike innocence and their world is colorful. The design of children's books should be designed in accordance with their reading habits and features at different times. Children's reading is roughly divided into two stages according to age.

\subsection{Preschoolers' reading before six years old}

In this stage, children often have mastered some simple poems and words through the guidance of their kindergarten teachers and parents. According to the survey and the sample tests, it can be found that the time for children to concentrate on books is very short. Even with the help of parents, the concentration time is less than 10 minutes. They begin to love pictures and albums that are mainly based on pictures and have simple text descriptions, including albums and photo albums that are colorful and well-structured and inspired their fantasy content. The most obvious reading change during this period is that they began to imitate the adults reading, reflecting the preschool children's innocent and naive desire for knowledge.

\subsection{Primary school children's reading before twelve years old}

During this period, children prefer books with strong storylines or cultural knowledge. As their ages gradually increase, they begin to become interested in all the good things in the natural world through textbooks. They hope to understand, familiarize with and explore the mysteries, and gradually have certain ability to accept and understand. This stage is the beginning of children's understanding of the objective world through books.

\section{Design Features of Children's Books}

Children's book design should be interesting to adapt to children's innocent, lively character traits, and be integrates into children's lives. While giving the children beautiful experience and sentiment, excellent children's book design can also bring them great pleasure and meet the requirements of their spiritual world, which is of great significance for the design of children's books. 


\subsection{Children's books design materials}

Children's books can be divided into paper books, cloth books, wooden books, plastic books, film books, touch sound books and toy books, depending on the materials used to make them. Because of the differences in materials, the form of books is also varied. No matter what kind of books, firstly, children's book materials should be zero-pollution to ensure children's health, and non-toxic and environmentally-friendly inks are used in the printing process. This is the most important for children's book materials. In the reading process, children often touch the books by hand, even kiss them with their mouths. This requires that children's book materials must be hygienic and healthy. Secondly, children's book materials should use safe, soft and light materials, instead of the hard and bulky materials. This can ensure that children are not scratched by materials during reading.

\subsection{Children's book design color}

Children have innate sensitivity to colors. Colors are like languages, which attracts children's attention to books and promotes their exploration and learning of book knowledge.

Children in the preschool period and the primary period can actively choose their favorite products. Color is an important factor for children to choose the goods. On the whole, colors are as colorful as children's rainbows in the sky. The colors the children like generally have the following features: firstly, the colors are saturated. Bright colors always jump into people's eyes for the first time, causing children's attention. Meanwhile, bright colors can bring joyful emotions to children, making their mood become happy and cheerful. Secondly, the features of color are reflected in the contrast between colors. We can see that in most books, contrasted colors and exaggerated color relationships often bring strong rhythm.

\subsection{Children's book design}

The prosperity of the children's book market and the diversified development of book forms are based on children's sensory experiences. Different forms of children's books give them different sensory experiences. In addition to hardcover books and paperback books, there are various types of books, such as cardboard books, folded books, digging holes, flip books and three-dimensional books. Different forms of books show children a different world, making them understand and recognize the world through books. With the increasing abundance of book materials and the continuous expansion of design thoughts, children's book forms will be more colorful to meet the needs of children.

\section{Features of the Children's Books Illustration Design}

Illustration design is a formal language that allows people to read and understand information content. Children's comprehension of language is weak. They are more sensitive to illustrations in books. Therefore, illustrations in children's picture books are particularly important. Illustration is an important medium for children to recognize the world and is always accompanied by children's physical and mental growth. When children begin to read, good illustration can promote their overall development by stimulating their imagination, inspiring their perceptions and developing their potential. Art can help children discover their own personalities and cultural traditional knowledge. The illustration art embodies our lives like music at any time. Different pictures allow children to have different psychological and physiological feelings so that they can fully understand the events and stories in the books. Illustrations can provide instant information and often can add details or humor that enrich the content of the book, the bright colors, attractive characters and expressions and artistic expressions.

\subsection{Visualization of children's book illustrations}

The rich and colorful presentation of the world leads to the children's requirements of colorful books. Based on this, in order to be able to guide children's greater interest in reading, the illustration designer should open the children's heart in the process of designing illustrations.

How to attract the children to immerse themselves in books and fall in love with reading. 
Illustrations in children's books play an important role. Being good illustrations in children's books, the most important significance of visualization lies in allowing children to visually understand information. Firstly, the visual characteristics of the illustration content should be clear. Either the characteristics of the characters or scenes and props, children should clearly understand the contents of the illustrations in the reading process. In this way, the illustrations and texts can correspond to each other and complement each other. Secondly, many children are visualized in these illustrations. They know what a circle is. They can also tell which animals are big and which are small. The most common things in everyday life such as brushing, wearing clothes and cycling are illustrated. They learn to understand from the illustrations.

An illustration must conform to a specific spatial assignment. If the text appears in the illustration, the illustration must provide a suitable space for it. Defining the important characters in the story requires the design of a special shape. Usually, most children's books have limited number of characters. Illustrations often have hero characters or some supporting characters. The illustration art must reflect the personality of the characters as perfectly as possible. Nowadays, children are provided with rich selections of images. Children enter the world of stories and knowledge through images. The communication media is filled with our life, which means that children are exposed to more images than ever before.

\subsection{Personalization of children's book illustrations}

The cultivation of individuality plays an important role in children's future creativity. Children's illustration is a world full of whimsy and creativity. Everyone can use their crayons to make full use of their unique imagination. Because children's personality is affected by congenital inheritance and acquired environment, education is very influential and childhood is the shaping period of good personality. The excellent design in children's book illustrations can mobilize children's curiosity in exploring unknown areas and enhance their intellectual development, making children's subjective initiative stimulated earlier and faster to achieve the goal of respecting children's own healthy growth. Excellent children's illustrations generally need to exaggerate, anthropomorphize and stylize the character images on the screen, which makes the works show certain imagination, interest, and distinctness, makes the works more exciting and makes the information more clearly conveyed. The proportion of children's picture books in children's education has also gradually increased, which requires the illustrators to create illustrations that are suitable for children's physical and mental development. Children's illustrations use anthropomorphic techniques to exaggerate people, animals, plants or things. They are lively, cute, vivid and full of spirituality. The same content uses different illustration style expressions to present children with different possibilities to maximize the development of children's personality.

\subsection{The art of children's book illustrations}

The illustration design in the book binding art should give the book beautiful artistic images, so that the readers can enjoy the beauty in the process of reading.

The children's illustrations have gained more and more attention and been loved by people in the form of picture books. With the increasing number of designers and readers, a large number of illustrations and picture books with different artistic styles have emerged, causing some worrying problems.

The lack of originality and plagiarism that has prevailed and brought new problems to the industry. A shrewd illustration without aesthetic taste cannot help the children understand the content of a literary work nor attract them to work on literary stories. Anastasiya Sokolovskaya, a Belarusian illustrator, has made a fantastic dream in winter for the children'sin the book named Little rabbit without a ticket. This gives children a quality visual experience. His paintings are like fairy tales, cute and dreamy. And these are all derived from the innocence of dependence, which is humorous for both the young and the old. The adults who read stories to children will also be happy.

For children, they are still in the best period of ignorance to explore the world, which means that the author of the illustrations is responsible for the responsibility of the children. The study of professional theories combining the children's aesthetic psychological features and illustrations is still 
a blank point in the theoretical study of the illustrations of children's books. In China, due to the late starting of the illustrations of children's books, theoretical research is relatively lagging behind. High-quality children's illustrations can lay a strong foundation for children to establish good aesthetic ability. Therefore, it is important to start from the children's aesthetic psychology, respect the children's book design principles, create a sensory experience and design rich and colorful children's books. The artistic illustration design in children's books lays the foundation for children's aesthetics. Each child has a good aesthetic education. They feel differently about the different forms and colors. Such cultivation make children have high standards of beauty. Some well-painted children's illustrations are not only very popular for children. The adults can also be inspired by the beauty when they accompany their children.

In conclusion, the excellent children's illustrations not only tell a story visually, but also use the artistic approach to cultivate their perception of beauty in the earliest period when children are exposed to books. From the aspect of design, children's book illustrations show the beauty of positioning accuracy and the precision of information transmission.
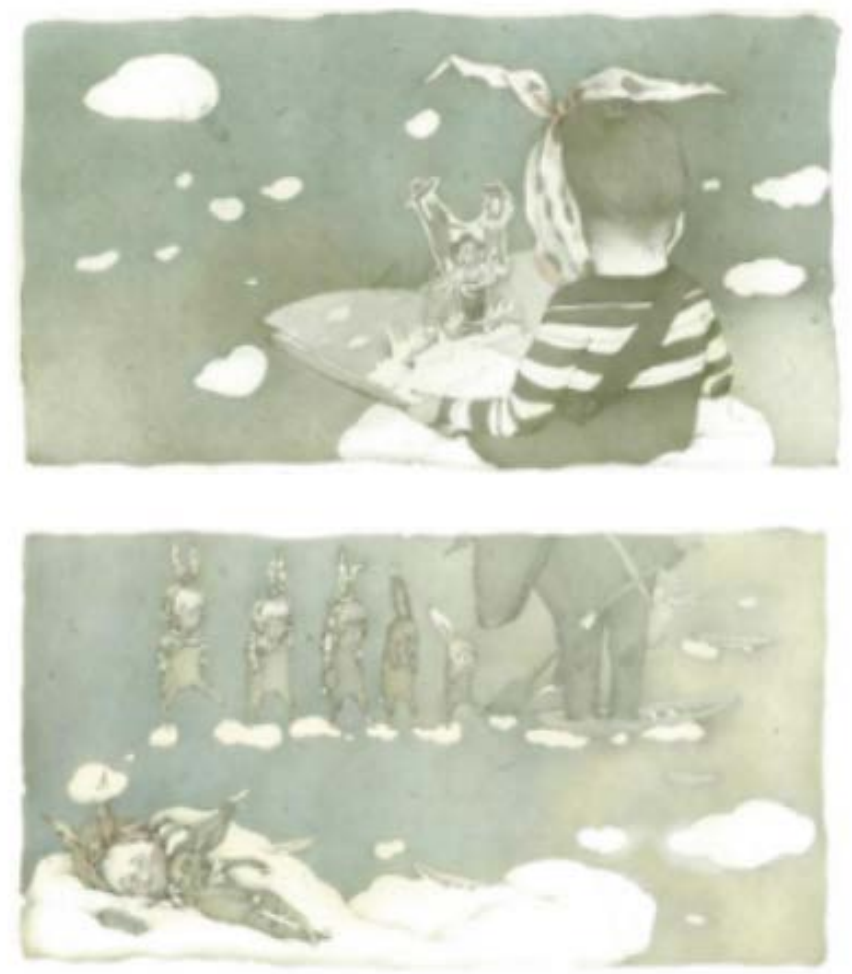

\section{References}

[1] S. Xiao. Exploration and Research on Children's Illustration in Art Design. Changchun University of Technology, 2010.

[2] Z. M. Xie. Research on Children's Illustration Painting Creation, J. DaWuTai (Bimonthly), (04) 2008.

[3] J. Lv. The Functions of Illustrations in Children's Literature, J. Journal of Chifeng University, (05) 2006. 